\title{
Tracoma em pacientes com conjuntivite alérgica
}

\author{
Trachoma in patients with allergic conjunctivitis
}

\author{
Haroldo de Lucena Bezerra ${ }^{1}$ \\ Glauco Igor Viana dos Santos ${ }^{2}$
}

Trabalho desenvolvido no Núcleo Especializado em Oftalmologia e Otorrinolaringologia - NEO - João Pessoa (PB) - Brasil.

${ }^{1}$ Doutor, Professor Adjunto da Disciplina de Oftalmologia da Universidade Federal da Paraíba - UFPB - João Pessoa ( PB ) - Brasil; Professor Titular do Centro Universitário de João Pessoa - UNIPÊ - João Pessoa ( PB ) - Brasil; Professor Titular da Faculdade de Ciências Médicas da Paraíba - FCMPB - João Pessoa (PB ) - Brasil; Professor Titular da Faculdade de Medicina Nova Esperança - FAMENE - João Pessoa ( PB ) - Brasil.

${ }^{2}$ Acadêmico do $10^{\circ}$ período do Curso de Graduação em Medicina da Universidade Federal de Campina Grande - UFCG.

Endereço para correspondência: Haroldo de Lucena Bezerra. Av. Monteiro da Franca, 1.051 - Apto. 1501 João Pessoa (PB) CEP 58038-320

E-mail: hdlucena@uol.com.br

Recebido para publicação em 28.09.2009

Última versão recebida em 26.01.2010

Aprovação em 07.06.2010

Os autores declaram que não possuem interesse financeiro com o referido estudo.

Nota Editorial: Depois de concluída a análise do artigo sob sigilo editorial e com a anuência da Dra. Luciane Bugman Moreira sobre a divulgação de seu nome como revisora, agradecemos sua participação neste processo.

\begin{tabular}{|c|}
\hline RESUMO \\
\hline 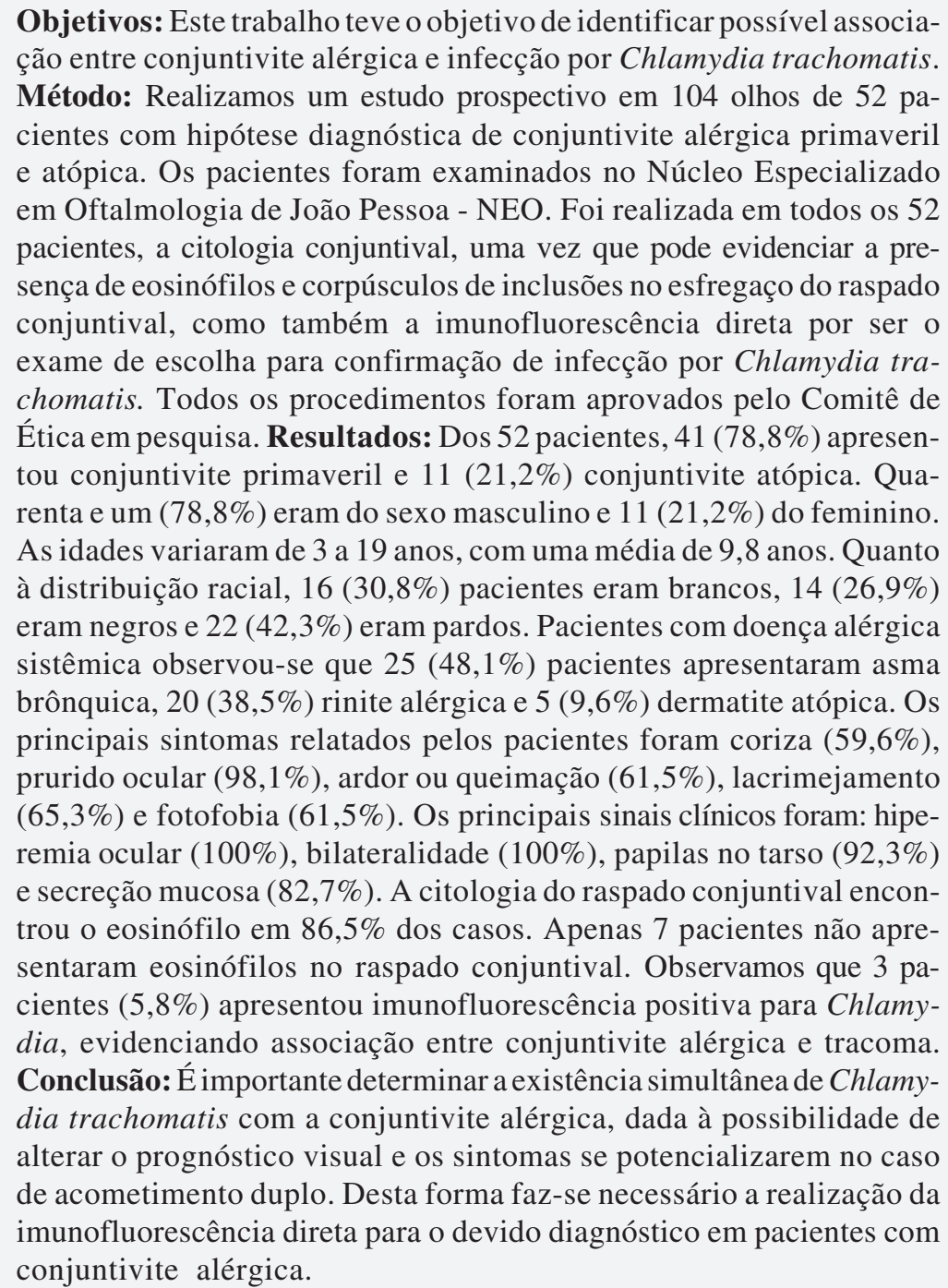 \\
\hline
\end{tabular}

Descritores: Conjuntivite alérgica/diagnóstico; Tracoma; Chlamydia trachomatis; Infecções por Chlamydia; Infecções oculares bacterianas; Imunofluorescência

\section{INTRODUÇÃO}

A conjuntivite alérgica é uma das mais comuns reações alérgicas e afeta cerca de 40 milhões de pessoas por ano somente nos Estados Unidos ${ }^{(1)}$.

Existem inúmeras classificações para as conjuntivites alérgicas ${ }^{(2-4)}$. Friedlaender ${ }^{(1)}$ sugere a divisão das conjuntivites alérgicas em: 1 - Conjun- 
tivite alérgica sazonal; 2 - Ceratoconjuntivite atópica; 3 Conjuntivite primaveril; 4 - Conjuntivite papilar gigante e 5 - Conjuntivite de contato.

A importância clínica da alergia ocular é devida mais a sua frequência do que sua gravidade, apesar de poder levar a cegueira, principalmente nos casos de ceratoconjuntivite atópica que pode produzir cicatrização corneana grave e perda de visão ${ }^{(5)}$.

O diagnóstico da conjuntivite alérgica é clínico, realizado somente após um completo exame médico, evidenciando-se uma história sistêmica e familiar de alergia, história de alergia ocular ou outras doenças alérgicas, exame biomicroscópico direcionado para as pálpebras, conjuntiva bulbar e tarsal, limbo e córnea ${ }^{(6)}$.

Os testes laboratoriais podem ser usados para corroborar com o diagnóstico, quando os sinais e sintomas são inconsistentes ou variáveis. Pode-se utilizar a citologia e a biópsia conjuntival ${ }^{(1)}$, além do teste de provocação conjuntival e avaliação das lágrimas. Na conjuntiva utilizamos a citologia esfoliativa ${ }^{(7)}$.

Herbert $^{(8)}$, em 1903, foi o primeiro autor a chamar atenção para a eosinofilia conjuntival no diagnóstico de conjuntivite alérgica e, até hoje, o diagnóstico laboratorial de alergia ocular frequentemente baseia-se na presença de eosinófilos na citologia conjuntival ${ }^{(9)}$.

Dentre as doenças que fazem diagnóstico diferencial com as conjuntivites alérgicas podemos citar o tracoma, síndrome de flacidez da pálpebra superior, ceratoconjuntivite límbica superior, olho seco, acne rosácea, penfigóide cicatricial, síndrome de Stevens-Johnson e blefaroconjuntivite ${ }^{(3,10)}$.

O tracoma é caracterizado por apresentar uma reação folicular na conjuntiva tarsal superior, enquanto que na conjuntivite alérgica os folículos são raros. Pode evoluir para cicatrizações na conjuntiva tarsal superior, surgindo as chamadas linhas de cicatrização de Arlt, além das fossetas de Herbert, que são cicatrizes limbares ${ }^{(10-11)}$. O diagnóstico do tracoma é eminentemente clínico, entretanto pode-se lançar mão da imunofluorescência $\operatorname{direta}^{(12)}$. Os eosinófilos não são vistos na citologia conjuntival como acontece na conjuntivite alérgica ${ }^{(13)}$, entretanto pode-se encontrar corpúsculos de inclusões ${ }^{(14)}$. O tracoma pode coexistir com a conjuntivite primaveril ${ }^{(4,14)}$.

O objetivo do presente trabalho é estudar a possível associação entre tracoma e conjuntivite alérgica através da imunofluorescência direta realizada em material obtido de raspado conjuntival.

\section{MÉTODOS}

Foi realizado um estudo prospectivo de pacientes com diagnóstico clínico de conjuntivite alérgica primaveril ou atópica atendidos no Núcleo Especializado em Oftalmologia e Otorrinolaringologia de João Pessoa - PB, após aprovação de Comitê de Ética em Pesquisa.

Os pacientes foram submetidos à propedêutica oftalmológica completa evidenciando-se os principais sinais e sinto- mas apresentados, além da história clínica pregressa de alergia. Foram excluídos do estudo os pacientes com quadro clínico atípicos e/ou com diagnóstico duvidoso e uso prévio de medicação.

Os pacientes foram divididos quanto ao tipo de alergia ocular apresentada e agrupados de acordo com os seguintes diagnósticos: ceratoconjuntivite atópica e ceratoconjuntivite primaveril.

Após a identificação, obtenção do consentimento livre esclarecido, exame clínico e diagnóstico confirmado, os pacientes foram encaminhados ao Laboratório e realizado a coleta de material conjuntival, totalizando 104 olhos de 52 pacientes.

No raspado conjuntival padronizou-se a realização do raspado das conjuntivas tarsal superior e inferior. Imediatamente após a realização do esfregaço, as lâminas foram submetidas à coloração pelo método de Giemsa.

A imunofluorescência para Chlamydia trachomatis foi realizada em todos os pacientes com o objetivo de identificar possível associação entre conjuntivite alérgica e infecção por Chlamydia trachomatis.

O material da conjuntiva tarsal superior foi colhido raspando-se com a espátula de Kimura e colocando-se o material dentro do círculo de lâmina específica para imunofluorescência para Chlamydia trachomatis, sem realizar esfregaço, sendo um círculo para cada olho. Após a coleta, fixa-se em metanol.

A análise dos esfregaços foi realizada por dois observadores de laboratórios distintos de maneira mascarada.

\section{RESULTADOS}

Foram examinados 52 pacientes, dos quais $11(21,2 \%)$ eram do sexo feminino e $41(78,8 \%)$ do sexo masculino. As idades variaram de 3 a 19 anos, com média de 9,8 anos. Dentre os tipos de conjuntivite alérgica observou-se que $41(78,8 \%)$ apresentaram diagnóstico clínico de conjuntivite primaveril e $11(21,2 \%)$ de ceratoconjuntivite atópica.

Quanto à distribuição racial, para o padrão brasileiro, 16 $(30,8 \%)$ pacientes eram brancos, 14 (26,9\%) eram negros, 22 $(42,3 \%)$ eram considerados pardos (para os quais admitimos a denominação de indeterminado) e nenhum paciente era da raça amarela.

O gráfico 1 mostra a distribuição porcentual dos pacientes que relataram história clínica de outras doenças alérgicas associada à conjuntivite alérgica. Observamos que 50 (96,1\%) pacientes apresentaram história clínica de doenças alérgicas associadas e $2(3,9 \%)$ não tiveram essa associação.

Os principais sintomas relatados pelos pacientes na fase aguda da conjuntivite alérgica foram coriza, prurido ocular, ardor ou queimação, dor ocular ou desconforto, edema palpebral, sensação de corpo estranho, lacrimejamento, fotofobia e visão borrada ou embaçamento visual.

O gráfico 2 mostra a distribuição porcentual dos principais sintomas relatados pelos pacientes durante a fase aguda da conjuntivite alérgica. 
A distribuição porcentual dos sinais clínicos apresentados pelos pacientes, na fase aguda da conjuntivite está enumerada na tabela 1 .

Com o objetivo de identificar um possível diagnóstico diferencial ou associação entre conjuntivite alérgica e infecções por Chlamydia trachomatis, a imunofluorescência direta foi realizada em todos os 52 pacientes. Três $(5,8 \%)$ pacientes apresentaram imunofluorescência direta positiva para Chlamydia trachomatis.

\section{DISCUSSÃO}

Em nossos pacientes com conjuntivite primaveril encontramos a faixa etária com média de 9,8 anos e mais frequente no sexo masculino, numa proporção de aproximadamente 4:1. Os dados demográficos dos nossos pacientes com conjuntivite primaveril coincidem com os da literatura ${ }^{(15-16)}$.

Dentre os pacientes com ceratoconjuntivite atópica a média de idade foi de 13,6 anos, valor este abaixo ao que é observado na literatura como pico de incidência, mas dentro do que é esperado para início da doença ${ }^{(1,17-18)}$. A ausência de faixas etárias mais avançadas pode representar que nossos pacientes encontram-se na fase inicial da doença. Também, em nosso meio, talvez esta ceratoconjuntivite comporte-se de maneira

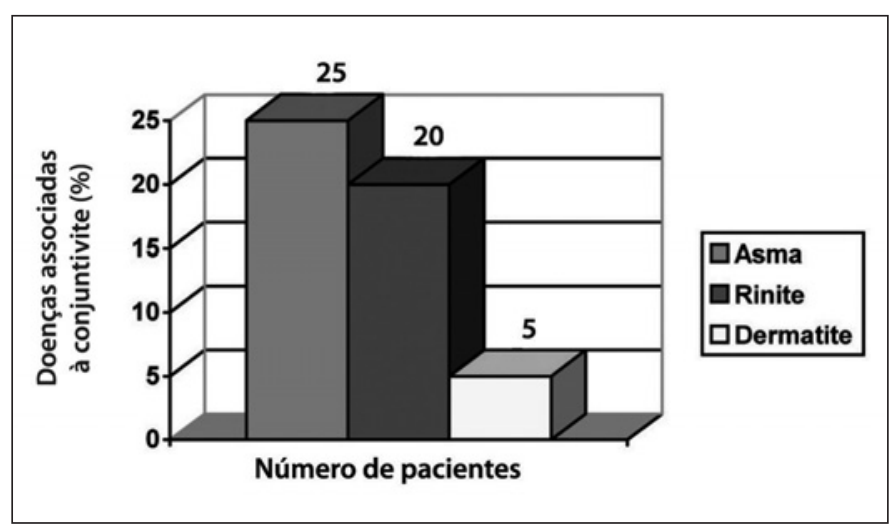

Gráfico 1 - Distribuição porcentual de doenças associadas à conjuntivite alérgica

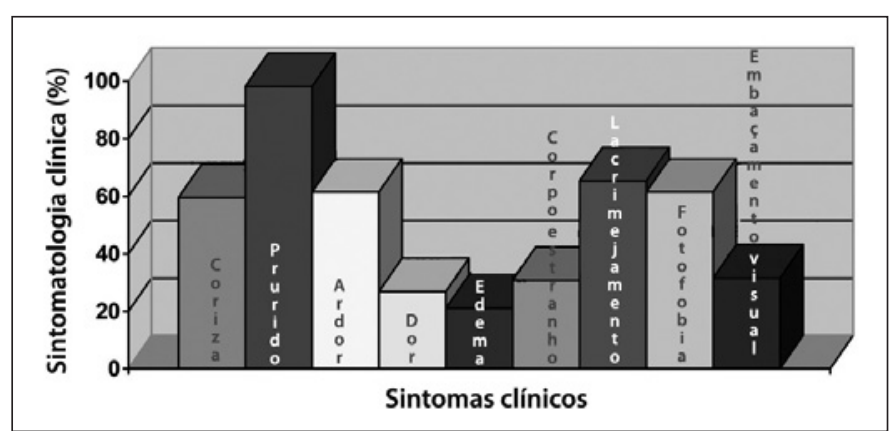

Gráfico 2 - Sinais clínicos apresentados em pacientes durante a fase aguda da conjuntivite alérgica diferente uma vez que não há dados epidemiológicos nacionais referentes a esta doença.

Há poucos dados disponíveis na literatura sobre a distribuição porcentual do acometimento de pacientes com conjuntivite alérgica quanto à raça. Em nosso estudo, levandose em consideração a miscigenação racial brasileira, houve uma distribuição uniforme entre os brancos $(30,4 \%)$, negros $(26,1 \%)$ e indeterminados $(43,5 \%)$; esses últimos assim denominados em virtude de não se enquadrarem em nenhum tipo racial. $\mathrm{O}$ acometimento em negros africanos pela conjuntivite primaveril foi descrito inicialmente por Dahan \& Appel ${ }^{(19)}$.

Relatos de outras doenças atópicas prévias ou associadas à conjuntivite têm sido frequentes em pacientes acometidos pela conjuntivite alérgica primaveril e atópica. Em nosso estudo, $25(48,1 \%)$ pacientes relataram história prévia de asma brônquica, 20 (38,5\%) queixaram-se de rinite alérgica, 5 pacientes $(9,6 \%)$ relataram serem portadores de dermatite atópica e apenas $2(3,9 \%)$ não tinham associações a outras alergias. Tuft et al. ${ }^{(17)}$, realizando um estudo com portadores de ceratoconjuntivite atópica, observaram distribuição porcentual maior de pacientes com história prévia de dermatite atópica eczematosa (95\%) e de asma (87\%). Power et al. ${ }^{(18)}$ relatou um porcentual de $65 \%$ para asma e rinite alérgica. Conforme Foster, a dermatite atópica é a patologia de maior frequência em associação com a ceratoconjuntivite atópica ${ }^{(20)}$.

Dentre os sintomas mencionados pelos pacientes, o prurido foi o mais proeminente, sendo relatado por $51(98,1 \%)$ dos pacientes na fase aguda da doença, concordando com os dados da literatura que referem o este sintoma como o mais importante sintoma da conjuntivite alérgica ${ }^{(21)}$.

Os sinais observados, descritos na tabela 1 , evidenciaram acometimento bilateral da conjuntivite alérgica em todos os

\begin{tabular}{|lcc|}
\hline \multicolumn{2}{|c|}{$\begin{array}{c}\text { Tabela 1. Distribuição absoluta e porcentual dos sinais clínicos } \\
\text { apresentados pelos pacientes portadores de conjuntivite alérgica, } \\
\text { em ambos os olhos na fase aguda da doença }\end{array}$} \\
Sinais clínicos & \multicolumn{2}{c}{ Pré-tratamento } \\
\cline { 2 - 3 } No & $\%$ \\
Bilateralidade & 52 & 100,0 \\
Hiperemia conjuntival & 52 & 100,0 \\
Quemose & 0 & 0 \\
Edema palpebral & 9 & 17,3 \\
Ceratite puntata & 36 & 69,2 \\
Pannus & 41 & 78,8 \\
Papilas no tarso & 47 & 90,2 \\
Papilas gigantes & 20 & 38,5 \\
Secreção & 43 & 82,7 \\
Cicatrização & 0 & 0 \\
Nódulos de Trantas & 27 & 51,9 \\
Blefarites & 32 & 61,5 \\
Úlcera em escudo & 0 & 0 \\
Pseudogerontoxon & 0 & 0 \\
Neovascularização & 9 & 17,3 \\
Opacidades corneanas periféricas & 18 & 34,6 \\
Limbo gelatinoso & 27 & 51,9
\end{tabular}


pacientes, apesar de, clinicamente, observarmos assimetria. As opacidades corneanas periféricas foram observadas em 18 $(34,6 \%)$ pacientes. Essas opacidades são conhecidas como pseudogerontoxon e são similares ao gerontoxon degenerativo ou arco senil que acomete o idoso ${ }^{(21)}$. A ceratite ponteada, também chamada de ceratite de Tobgy, é causada pelo efeito tóxico das substâncias liberadas pelos eosinófilos e indica o nível de atividade da doença ${ }^{(22-23)}$. Foi observada em $36(69,2 \%)$ dos pacientes avaliados.

Observamos a blefarite estafilocócica em pacientes com conjuntivite primaveril, apesar de comprovadamente ser mais frequente na ceratoconjuntivite atópica. A cicatrização da conjuntiva tarsal superior não foi observada em nenhum paciente. Poderíamos esperar o surgimento desse sinal em pacientes com a ceratoconjuntivite atópica, entretanto pela média de idade mencionada anteriormente (13,6 anos), podemos sugerir que a doença é de aparecimento recente e não evoluiria tão rapidamente a ponto de observarmos a cicatrização no tarso superior dos mesmos ${ }^{(16-18)}$

O eosinófilo é a principal célula envolvida no diagnóstico da alergia ocular evidenciada através da citologia do raspado conjuntival, sendo considerada a célula característica da inflamação alérgica ${ }^{(23-24)}$. Sua ausência no raspado conjuntival não exclui o diagnóstico de alergia ocular ${ }^{(25-27)}$. Apesar de não encontrado no esfregaço do raspado conjuntival, é possível evidenciar eosinófilos na substância própria da conjuntiva de indivíduos com conjuntivite alérgica, não sendo necessariamente evidenciados no epitélio ${ }^{(25,27)}$. Constatamos isto neste estudo quando se observou que apenas $7(13,5 \%)$ pacientes não apresentaram eosinófilos na citologia conjuntival. Na fase aguda da conjuntivite alérgica, o eosinófilo foi encontrado em $86,5 \%$ dos casos, 45 pacientes, consubstanciando assim os dados da literatura, uma vez que a prevalência de eosinófilos na citologia do raspado conjuntival pode variar de 20 a $80 \%{ }^{(25,27-29)}$.

A degranulação dos mastócitos promove a liberação de mediadores inflamatórios e dentre estes podemos citar o fator quimiotáxico eosinofílico, responsável pela quimiotaxia dos eosinófilos para os tecidos conjuntivais ${ }^{(6,30)}$. O próprio prurido ocular, através de um mecanismo irritativo pode recrutar células inflamatórias para a conjuntiva ${ }^{(31)}$.

A ocorrência simultânea de conjuntivite alérgica e tracoma tem sido sugerida na literatura ${ }^{(4,14-15)}$. Os achados clínicos de ambas as doenças se interagem, podendo coexistir papilas gigantes e folículos no tarso superior. Os folículos também podem ser observados no limbo, entretanto a presença de papilas limbares e o edema do limbo, peculiar da conjuntivite alérgica, podem obscurecê-los. No caso de acometimento duplo, os sintomas se potencializam, sendo mais intensos do que nos indivíduos que apresentam uma única patologia. Neste caso a citologia representa um importante método de diagnóstico, uma vez que pode evidenciar a presença de eosinófilos e corpúsculos de inclusões no esfregaço do raspado conjuntival ${ }^{(14)}$. Em nosso estudo não foi encontrado nenhum corpúsculo de inclusão, o que não invalida esse método de diagnóstico, e sim faz crer na necessidade da realização de outro exame associado. Pois é importante determinar a existência simultânea do tracoma com a conjuntivite alérgica, dada à possibilidade de alterar o prognóstico visual da conjuntivite. Além disso, o tracoma, na condição de doença incapacitante pela possibilidade de evolução para a cegueira, deve ser sempre diagnosticado.

Foi realizada a imunofluorescência direta em todos os 52 pacientes com o objetivo de identificar um possível diagnóstico diferencial ou associação entre a conjuntivite alérgica e infecções por Chlamydia trachomatis. Observamos que 3 pacientes $(5,8 \%)$ apresentaram imunofluorescência direta positiva para Chlamydia, evidenciando associação entre conjuntivite alérgica e tracoma. A imunofluorescência direta é o exame de escolha para confirmação de infecção por Chlamydia trachomatis ${ }^{(12)}$. Nos casos de conjuntivite alérgica com suspeita de infecção concomitante pela Chlamydia trachomatis faz-se necessário a realização da imunofluorescência direta. A literatura tem mostrado bons resultados no diagnóstico de tracoma pela positividade do teste ${ }^{(32-33)}$.

\section{CONCLUSÃO}

É importante determinar a existência simultânea de Chlamydia trachomatis com a conjuntivite alérgica, dada à possibilidade de alterar o prognóstico visual e os sintomas se potencializarem no caso de acometimento duplo. Desta forma fazse necessário a realização da imunofluorescência direta para o devido diagnóstico em pacientes com conjuntivite alérgica.

\section{ABSTRACT}

Purpose: The aim of this paper was to identify a possible association between allergic conjunctivitis and Chlamydia trachomatis infection. Methods: A prospective study was carried out in 104 eyes of 52 patients with diagnosis of vernal conjunctivitis and atopic keratoconjunctivitis. Conjunctival cytology was performed in all the 52 patients, once it can evidence eosinophils presence and inclusions corpuscles in the conjunctival scraping smear, as well as the direct immunofluorescence that is the choice exam for Chlamydia trachomatis infection confirmation. All procedures were approved by the Institutional Review Board Ethics Committee. Results: Of the 52 patients, 41 (78.8\%) presented vernal conjunctivitis and $11(21.2 \%)$ atopic keratoconjunctivitis. Forty-one patients (78.8\%) were male and $11(21.2 \%)$ female. The ages varied from 3 to 19 years, with an average of 9.8 years. Regarding racial distribution, 16 (30.8\%) patients were caucasian, 14 (26.9\%) were black and $22(42.3 \%)$ were brown. Regarding systemic allergic diseases, it was observed that $25(48.1 \%)$ patients presented asthma, $20(38.5 \%)$ allergic rhinitis and $5(9.6 \%)$ atopic dermatitis. The main symptoms complained by the patients were coryza $(59.6 \%)$, 
ocular itching $(98.1 \%)$, burning $(61.5 \%)$, tearing $(65.3 \%)$ and photophobia $(61.5 \%)$. The main clinical signs were: ocular hyperemia $(100 \%)$, bilaterality $(100 \%)$, superior tarsal papilla $(92.3 \%)$ and mucous secretion $(82.7 \%)$. The cytology of the conjunctival scrapings found eosinophil in $86.5 \%$ of the cases. Only seven patients did not present eosinophils in the conjunctival scrapings. Three patients $(5.8 \%)$ presented positive immunofluorescence for Chlamydia, evidencing an association between allergic conjunctivitis and trachoma. Conclusion: It is important to determine the simultaneous coexistence of Chlamydia trachomatis and allergic conjunctivitis, due to the possibility to change the visual prognostic and of symptoms potentiation in case of double attack. Therefore, it is necessary to performe direct immunofluorescence for the correct diagnosis in patients with allergic conjunctivitis.

Keywords: Conjunctivitis, allergic/diagnosis; Trachoma; Chlamydia trachomatis; Eye infections, bacterial; Fluorescent antibody technique

\section{REFERÊNCIAS}

1. Friedlaender MH. Conjunctivitis of allergic origin: clinical presentation and differential diagnosis. Surv Ophthalmol. 1993;38 Suppl:105-14. Review.

2. Ehlers WH, Donshik PC. Allergic ocular disorders: a spectrum of diseases. CLAO J. 1992;18(2):117-24. Review.

3. Brunzini R. Conjuntivopatías alérgicas: diagnóstico diferencial. Arch Argent Alerg Inmunol Clin. 1994;25(4):XIX-XI.

4. Buckley RJ. Allergic eye disease-a clinical challenge. Clin Exp Allergy. 1998; 28 Suppl 6:39-43.

5. Ghoraishi M, Akova YA, Tugal-Tutkun I, Foster CS. Penetrating keratoplasty in atopic keratoconjunctivitis. Cornea. 1995;14(6):610-3.

6. Butrus SI, Abelson MB. Laboratory evaluation of ocular allergy. Int Ophthalmol Clin. 1988;28(4):324-8. Review.

7. Stenson S. Cytologic diagnosis. A. The anterior segment cytopathology. In: Karcioglu ZA. Laboratory diagnosis in ophthalmology. New York: MacMillan Publishing Company; 1987. p.90-107.

8. Herbert H. Preliminary note on the pathology and diagnosis of spring catarrh. Br Med J. 1903;2(2230):735.
9. Friedlaender MH. Ocular allergy. Int Ophthalmol Clin. 1985;25(2):35-41.

10. Udell IJ. Differential diagnosis of ocular allergy. Int Ophthalmol Clin. 1988; 28(4):275-81. Review.

11. Scarpi MJ, Gentil R. Sinais e sintomas do tracoma em povoado do Estado da Bahia-Brasil. Arq Bras Oftalmol. 1990;53(6):276-8.

12. Medina NH, Gentil RM, Caraça M, Suzuki CK, Melles HHB. Análise de exames de imunofluorescência direta para o diagnóstico de tracoma. Rev Saúde Pública=J Public Health. 1996;30(2):135-40.

13. Allansmith MR. Vernal conjunctivitis. In: Duane TD. Clinical ophthalmology. Philadelphia: Harper \& Row Publishers;1981. v.4. c.9. p.1-7.

14. Friedlaender MH, Cameron J. Vernal keratoconjunctivitis and trachoma. Int Ophthalmol. 1988;12(1):47-51.

15. Neumann E, Gutmann MJ, Blumenkrantz N, Michaelson IC. A review of four hundred cases of vernal conjunctivitis. Am J Ophthalmol. 1959;47(2):166-72.

16. Buckley RJ. Vernal Keratoconjunctivitis. Int Ophthalmol Clin. 1988;28(4):303-8.

17. Tuft SJ, Kemeny DM, Dart JK, Buckley RJ. Clinical features of atopic keratoconjunctivitis. Ophthalmology. 1991;98(2):150-8.

18. Power WJ, Tugal-Tutkun I, Foster CS. Long-term follow-up of patients with atopic keratoconjunctivitis. Ophthalmology. 1998;105(4):637-42.

19. Dahan E, Appel R. Vernal keratoconjunctivitis in the black child and its response to therapy. Br J Ophthalmol. 1983;67(10):688-92.

20. Foster CS, Calonge M. Atopic keratoconjunctivitis. Ophthalmology. 1990; 97(8):992-1000.

21. Braude LS, Chandler JW. Atopic corneal disease. Int Ophthalmol Clin. 1984 24(2):145-56

22. Friedlaender MH. Allergic disorders of the peripheral cornea. Int Ophthalmol Clin. 1986;26(4):69-75

23. Freitas D, Belfort Júnior R. Conjuntivites. Arq Bras Oftalmol. 1992;55(5):196-205.

24. Thygeson P. The cytology of conjunctival exudates. Am J Ophthalmol. 1946; 29(12):1499-512.

25. Abelson MB, Madiwale N, Weston JH. Conjunctival eosinophils in allergic ocular disease. Arch Ophthalmol. 1983;101(4):555-6.

26. Abelson MB, Udell IJ, Weston JH. Conjunctival eosinophils in compound 48/80 rabbit model. Arch Ophthalmol. 1983;101(4):631-3.

27. Friedlaender MH, Okumoto M, Kelley J. Diagnosis of allergic conjunctivitis. Arch Ophthalmol. 1984;102(8):1198-9.

28. Stenson S, Newman R, Fedukowicz H. Laboratory studies in acute conjunctivitis. Arch Ophthalmol. 1982;100(8):1275-7.

29. Kari O. Atopic conjunctivitis.A cytologic examination. Acta Ophthalmol (Copenh). 1988;66(4):381-6.

30. Wasserman SI, Goetzl EJ, Austen KF. Preformed eosinophil chemotactic factor of anaphylaxis (ECF-A). J Immunol. 1974;112(1):351-8.

31. Greiner JV, Peace DG, Baird RS, Allansmith MR. Effects of eye rubbing on the conjunctiva as a model of ocular inflammation. Am J Ophthalmol. 1985; 100(1):45-50.

32. Scarpi MJ, Silva RJM, Ferreira IA, Barbosa FAC, Plut RCA. Prevalência de tracoma em bairro do município de Palmares, Estado de Pernambuco, Brasil. Arq Bras Oftalmol. 1990;53(4):171-4.

33. Morschbacher R, Scarpi MJ. Prevalência de tracoma no parque indígena do Xingu. Arq Bras Oftalmol. 1996;59(1):83-7.

Nos aptigos enviados papa publitagta, o nome dos autores \& suas afiliagúgs devem estar completos. Isso facilitapá a indexagấ e os links com as bases de dados o o BV Laties. 